\title{
PERIODISMO LITERARIO: ENTRE LA LITERATURA CONSTITUTIVA Y LA CONDICIONAL
}

\author{
Fernando López Pan \\ Universidad de Navarra \\ lopezpan@unav.es
}

\begin{abstract}
Resumen: La polémica acerca del periodismo literario no se puede considerar definitivamente zanjada, pero es indudable que el género ha logrado consolidarse en el ámbito académico. Este artículo da una visión general de su proceso de legitimación; especialmente en España, donde destaca el articulismo literario. Esa perspectiva general servirá de marco para explicar cómo pueden incorporarse formas expresivas del periodismo narrativo y del articulismo a la Literatura. Para ello, el trabajo se apoya en la distinción planteada por Genette entre literatura constitutiva y literatura condicional.
\end{abstract}

Palabras clave: Periodismo literario, articulismo, periodismo y literatura.

Abstract: The controversy about Literary journalism is not definitively settled, but there is no doubt that Literary journalism has been consolidated in the academic field. This article gives an overview of the process of legitimation, mainly in Spain, where the literary articles have a large tradition. This overview will provide a framework to explain how is possible to incorporate journalistic genres into the Literature field. For this, the work relies on Genette's distinction between constitutive and conditional literature.

Keywords: Literary journalism, feature writing, journalism and literature. Newspaper Writing

\section{INTRODUCCIÓN}

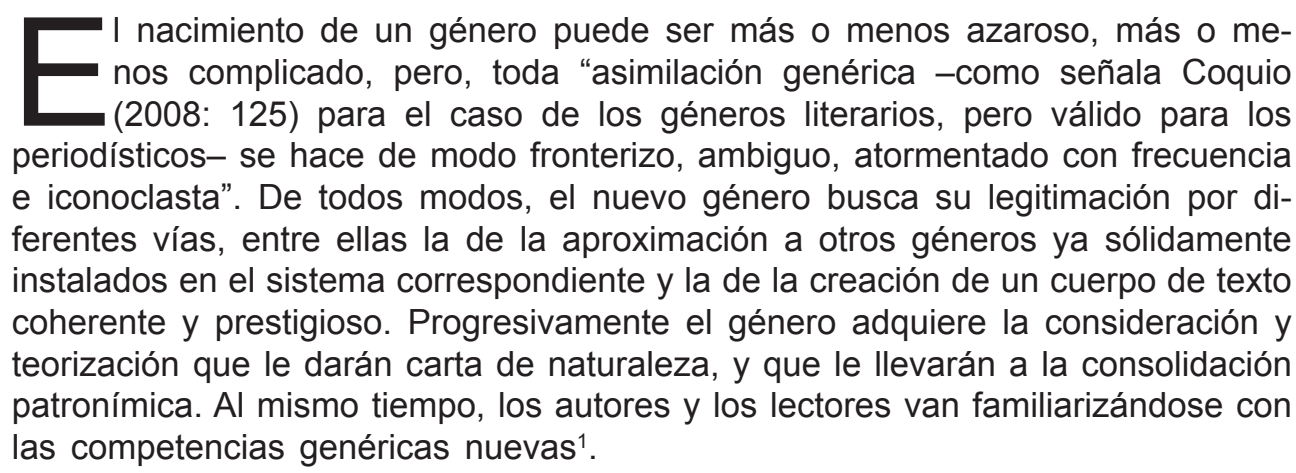

${ }^{1}$ Sintetizo en este párrafo ideas tomadas de Moncond’huy y Scepi (2008) y Coquio (2008). 
En el ámbito del periodismo, en el último tercio del siglo pasado se ha ido abriendo paso el llamado Periodismo literario, un género que ampara los siguientes subgéneros²:

1. Géneros con más tradición y presencia en el periodismo español: la crónica, liberada "de las graves responsabilidades del reportaje en lo que hace a la indagación y al contraste de fuentes" (Chillón, 1999: 377), la entrevista, artículo de opinión, de naturaleza narrativa, anecdótica o ensayística, y la columna.

2. Géneros con menor presencia en España, y dominantes en el periodismo anglosajón. En primer lugar, el reportaje-novelado: textos de intencionalidad periodística que "incorporan algunos recursos compositivos y estilísticos de origen novelesco, pero sin que tal asimilación sea completa" (Chillón, 1999: 193). Cuando tienen que someterse a los límites de brevedad, los textos se asemejan más al relato o la short-story, ya que el periodista se ve forzado a compactar la historia "mediante sumarios narrativos, condensaciones temporales, descripciones precisas y diálogos escrupulosamente escogidos y quintaesenciados" (Chillón, 1999: 266). En segundo lugar, la novela-reportaje o novelas de no ficción: textos que asimilan "sin límites las técnicas de composición y estilo propias de la novela realista clásica" (Chillón, 1999: 194). Los autores de esos textos utilizan fuentes de primera mano, observan en directo situaciones y escenas cotidianas, registran el diálogo, etc. Y, por último, el perfil. Nace en Estados Unidos en la revista New Yorker en los años 20 del sigo pasado, de la mano de su director Harold Ross, quien creó la sección Profile. Los escritores no querían dar declaraciones públicas y empezaron a elaborar retratos de personas. Eran textos de 40 o 50 folios con investigaciones a fondo sobre personajes: iban muy a la raíz. El primer escritor de perfiles fue Alva Jhonson, luego le siguieron Lillian Ross, Truman Capote (el dique en sus dominios, Retratos), Norman Mailer, etc. Ya en los años 70 recibe un fuerte impulso con el Nuevo Periodismo, muy vinculado a la gente y muy preocupado por vincular personas a acontecimientos.

Si toda innovación genérica es tormentosa, en el caso del llamado Periodismo literario esas turbulencias se duplican porque deben hacerse en simultáneo en dos sistemas de géneros: el periodístico y el literario, con índices de apertura diferentes. Por un lado, el literario es un sistema muy dinámico, donde la academia acepta los fenómenos de atracción y contaminación entre los géneros. Ahora bien, durante mucho tiempo, había marginado el estudio de lo literario en la actividad periodística. Por otro, el periodístico, por su parte, hasta fechas muy recientes, ha sido más estático, combinado durante mucho tiempo lo que se podría calificar como géneros de funcionamiento rutinario (esquelas, tablas de

\footnotetext{
${ }^{2}$ La clasificación se hace a partir de la propuesta de Chillón (1999), y agrupando los géneros según su relevancia en España.
} 
resultados, mapas del tiempo, etc.) con géneros con códigos fijados, pero que admiten variaciones. Además, se ha construido en cierta medida por oposición al de la literatura. Se entiende bien que la irrupción del llamado Periodismo literario -con sus amplios márgenes de libertad- se encontrara con tanta resistencia por parte de los estudiosos.

También se explica esa rigidez por la función social asignada al periodismo, por el perfil de los lectores a los que se dirige y por una preocupación ética básica en la profesión periodística -al menos en la tradición occidental- que se asienta sobre unos determinados presupuestos epistemológicos; entre ellos, la separación de hechos y opiniones y la búsqueda de la objetividad, "caracterizada como la suma de varios factores: neutralidad, imparcialidad, equilibrio y equidad, renuncia a tomar partido político, veracidad, factualidad, precisión y exhaustividad (completesness)" (Chalaby, 1998: 130), que levantan un muro entre el relato y el comentario, entre el periodismo y la literatura.

En cualquier caso y aunque la polémica no se pueda considerar definitivamente zanjada, los géneros del llamado Periodismo literario han logrado una indiscutible consolidación en el ámbito académico. Precisamente, en el primer epígrafe de este artículo se dará una visión general del proceso de adaptación, aceptación y legitimación académica de esos géneros. Tras unas breves referencias al ámbito anglosajón, nos centraremos en el caso español, que dará pie al segundo epígrafe, en el que se aborda el articulismo, género que está en el origen de la polémica entre periodismo y literatura en nuestro país. Ambos epígrafes servirán de marco y contexto para lo que se pretende en el tercero de este artículo: explicar teóricamente si es posible y cómo es posible la incorporación de esos géneros a la Literatura, condición indispensable para que puedan bautizarse con el adjetivo de literario. Para ello, nos serviremos de la teoría sobre la literariedad desarrollada por Genette, quien a nuestro juicio da algunas claves que pueden resolver ciertas dudas acerca de la naturaleza del Periodismo literario. Aparte de la propuesta y las conclusiones de este trabajo, que se asientan en la teoría de Genette, un objetivo secundario es el de allegar herramientas conceptuales de la teoría literaria que ayuden a explicar la realidad de la práctica periodística.

\section{HACIA LA LEGITIMACIÓN ACADÉMICA DE UN GÉNERO}

Chalaby (1996: 303) sostiene que el periodismo actual es una invención angloamericana. A su juicio, el concepto de noticia y la importancia de la información; las prácticas discursivas del reporterismo y la entrevista; el relato centrado en los hechos y construido de un modo específico; junto con las cuestiones epistemológicas y éticas señaladas más arriba, son productos originarios del periodismo anglosajón que acabaron ejerciendo su hegemonía sobre otras tradiciones.

De ahí que en Estados Unidos esa separación entre el periodismo y la literatura fuera tajante y temprana, tan tajante y tan temprana que se explica la virulencia -tanto por parte de los promotores y defensores como por parte de 
los críticos- con la que se desarrolló en los años 70 el fenómeno del Nuevo Periodismo, precisamente el que trajo a un primer plano en ese país el debate acerca de las relaciones entre ambas prácticas, y dio cuerpo a lo que se tiende a denominar hoy Periodismo literario. Un tipo de periodismo que en ese ámbito geográfico ${ }^{3}$ "sólo designa a la narración periodística. De tal manera que el término anglosajón Literary Journalism es más o menos sinónimo de la expresión española 'periodismo narrativo"” (Gutiérrez Palacio, 2009: 33).

Esa exclusividad de lo narrativo se refleja en los nombres con los que se alude al nuevo género: reportaje de no ficción, literatura de no ficción, no ficción creativa, al arte de los hechos, novela de no ficción, ficción ensayística, ficción factual, literatura de hechos, literatura no imaginativa (Hartsock, 1999: 433) . También se advierte en las definiciones: Kramer (1995), por ejemplo, acoge bajo la etiqueta Periodismo literario aquel "tipo de texto en el que las artes estilísticas y de construcción narrativa asociadas desde siempre con la literatura de ficción ayudan a atrapar la fugacidad de los acontecimientos, que es la esencia del periodismo". Y, en el prefacio del primer número de la revista Literary Journalism Studies, el editor afirma que el ámbito específico de esa publicación es lo que llama "periodismo descriptivo-narrativo (narra-descriptive journalism) con ambición literaria" (Hartssock, 2009: 5).

Al margen de que se ciña a los textos narrativos -reportaje novelado, novela reportaje y perfil-, y a pesar de que fue desdeñado por los críticos literarios y la literatura académica y por los críticos del Periodismo y la "mass communication Academy" hasta bien entrados los años 90 (Hartsock, 1998); es innegable que donde más ha madurado el nuevo género y donde más se ha reflexionado sobre él ha sido en Estados Unidos. De hecho, varios estudiosos americanos están en el origen de International Association for Literary Journalism Studies (IALJS) que desde $2006^{5}$ organiza un congreso anual y desde 2009 publica la revista académica Literary Journalism Studies. Que el editor de la revista sea norteamericano y que el artículo programático del número 1 lleve la firma de Norman Sims hablan de la preponderancia académica estadounidense. Durante mucho tiempo, los académicos dedicados a este estudio han comprendido que ahí hay un valor crítico y cultural en este descuidado género. El número inaugural de esta revista sirve para demostrar que la academia ha alcanzado su madurez (Hartsock, 2009: 5).

De todos modos, la IALJS es consciente de que se trata de un primer paso, por eso señala en su página web como uno de sus objetivos "asegurar la aceptación del periodismo literario y del reportaje literario como un legítimo tema académico

\footnotetext{
${ }^{3}$ Algo similar a lo que sucede en Hispanoamérica -añade-, donde ese tipo de Periodismo "se manifiesta en la crónica, el reportaje y otros derivados" (2009: 36).

${ }^{4} \mathrm{Y}$ otros dos difícilmente traducibles: artjournalism y journalit.

${ }^{5}$ En concreto, el 14 de julio de 2006, tras el Primer Congreso Internacional sobre Periodismo Literario celebrado en la Universidad francesa de Nancy.
} 
tanto en los Departamentos de Inglés como en los de Periodismo". Y al mismo tiempo, se compromete a "explorar los límites de lo que se define como "periodismo literario" tanto en el pasado como en el presente".

A diferencia del ámbito angloamericano, en los países del área mediterránea -especialmente Italia, Grecia y España-, las relaciones entre periodismo y literatura han estado muy presentes desde los orígenes y "se sienten todavía hoy, determinando un modelo de periodismo que tiene preferencia por el comentario, la interpretación y la evaluación de los acontecimientos y las situaciones" (Mancini, 2005: 85). Un periodismo que "presta más atención a la escritura 'literaria' que a la simple y escueta narración de hechos, que constituye la prerrogativa esencial del periodismo en el sentido moderno del término" (Ibídem: 83).

Para el caso español, es bien conocida la cita de Acosta Montoro (1973: 51): "El mundo del periodismo, en los orígenes y en las épocas de su primer desarrollo, fue el mundo de la literatura". Y todavía en los años 50 y los 60 esa relación entre ambas prácticas discursivas era apreciada por conocidos profesores de las escuelas de periodismo ${ }^{6}$. Sirvan de muestra dos ejemplos. González Ruiz (1953: 130), además de criticar a los manualistas estadounidenses por levantar muros poco menos que inexpugnables entre la literatura y el periodismo, afirma lo siguiente:

la narración periodística es una parte de la narración literaria. Se nos comprenderá si decimos que no toda buena narración literaria es periodística, pero sí toda buena narración periodística es literaria [...]. Lo que está correcta, clara y concisamente escrito, empleando las palabras propias y diciendo exactamente lo que se quiere decir, es periodístico y es literario. [...]. La narración periodística es una narración literaria pero con limitaciones.

Y Martín Vivaldi -en 1973- señalaba que "es difícil, aun hoy, encontrar la línea de demarcación definida entre lo que llamamos literatura y lo que denominamos periodismo" (75) y mencionaba a grandes escritores que publicaban entonces "no sólo artículos más o menos literarios, sino también grandes reportajes informativos" (46): por mencionar algunos, como Castillo Puche, pero sobre todo José María Gironella, "cuyas obras Personas, ideas y mares y El Japón y su duende son un ejemplo del mejor periodismo literario o de la mejor literatura periodística" (47). Y apuesta porque el futuro pertenecerá "a los periódicos hechos por periodistas-escritores" (201). Por "periódicos bien escritos -prosigue Martín Vivaldi-, en los que cada línea haya sido pensada, y en los que cada frase, a más de su elegancia, esté cargada de sentido. El futuro, en suma, pertenece a los perió-

\footnotetext{
${ }^{6}$ Merece la pena destacar un excelente trabajo sobre las relaciones entre el periodismo y la literatura publicado por Gómez Alfaro en Gaceta de la Prensa Española en 1960. Rodríguez Rodríguez (2010) ha mostrado lo ambicioso de ese trabajo, el grado de madurez y la dimensión interdisciplinar en la que se basa.
} 
dicos hechos por periodistas escritores" (1973: 22). Por eso no resulta extraña su afirmación de que "en la práctica, cada reportero, cronista o articulista" debe escribir "'a su aire', sin demasiadas preocupaciones metodológicas ni científicas. ¡Aviado estaría el periodista que, antes de escribir una crónica, un reportaje o un artículo de actualidad, tuviera que recurrir al 'Libro de estilo' para seguir unas normas de procedimiento!" (22). O esta otra: "Parece que los moldes expresivos van perdiendo puntos. El formalismo se doblega ante la personalidad del periodista-escritor. Personalidad que cada día se va imponiendo cada vez más, a expensas de unas estructuras estilísticas -'made in USA'- cuya inamovilidad está por demostrar. En un periódico interesa sobremanera una buena 'pluma, con nervio, con 'garra', con estilo propio, mejor que un redactor estandarizado, por no decir adocenado, contrahecho, a fuerza de seguir una pauta impuesta por circunstancias profesionales meramente históricas. Si hubo un modo de 'hacer' periodismo a principios o mediados de siglo, no quiere decir que siempre haya que seguir haciéndolo de idéntica manera" (57). He reproducido extensamente estas afirmaciones de Martín Vivaldi, porque recuerdan a muchas de las que hace Chillón y porque sirven de botón de muestra de cómo el estudio pendiente de la historia de la RP permitiría redescubrir lo que a veces se presenta como novedoso y rescatar actitudes e ideas útiles, interesantes y enriquecedoras.

Sin embargo, en los años 70 , el mundo académico español construyó su discurso, en particular el de los géneros, en torno a los principios del periodismo anglosajón mencionados más arriba. Muy probablemente influyó la necesidad de abrir un hueco para los estudios de Periodismo en el mundo universitario, al que habían accedido en 1971; el empeño por dar envergadura universitaria a una materia hasta entonces limitada a enseñar las destrezas expresivas de la profesión; y la exigencia académica de separar la disciplina y su objeto de estudio de otras similares o cercanas, en especial de la literatura y la lengua.

Así, el paradigma dominante (Vidal, 2002) -al menos en los años 70 y 80- trazó unas fronteras rígidas entre el Periodismo y la Literatura. De hecho, Martínez Albertos (1978: 123) llegó a ver la deriva literaria como una amenaza al periodismo y a su finalidad de "transmitir datos e ideas de interés general a través del periódico o de cualquier otro medio de comunicación de masas". El texto periodístico, afirmaba, busca la rápida y eficaz transmisión de datos, la claridad y la sencillez que permitan entenderlo fácilmente. Y Aguilera (1992: 18), uno de sus discípulos, remachaba la separación entre ambas actividades al decir que "periodismo, en su sentido estricto y exacto, equivale a información de actualidad. Es decir: que en un periódico, o en un medio de comunicación social no escrito, cabe casi todo, pero no todo es periodismo en el sentido exacto de la palabra, porque no todo es información de actualidad". Se explica la escasa atención que desde las facultades se prestó a ese periodismo de tintes literarios que circulaba por los medios.

El año 1985, con la publicación por parte de Bernal y Chillón del libro Periodismo informativo de creación, se inicia una reacción contra el paradigma 
dominante y un sistema de géneros que no dejaba espacio para el periodismo más creativo. Desde entonces, Chillón $(1999,2006)$ se ha dedicado con ahínco a estudiar las relaciones entre Periodismo y Literatura. Es el primer autor, tanto entre los estudiosos del periodismo como los de la literatura, que lo hace de un modo sistemático, en el que combina la reflexión teórica con el estudio de la práctica y el ejercicio de ambas actividades. Entre sus objetivos está el de redefinir la naturaleza de ambos discursos, encontrando acomodo a las nuevas formas expresivas que, a su juicio, muestran que "las fronteras tradicionalmente trazadas" entre ficción y no ficción han desaparecido, algo que afecta no sólo al estilo, sino también a cuestiones epistemológicas (1999: 195): entre otras, la naturaleza del lenguaje y del pensamiento (y de las relaciones entre ellos), la noción de símbolo e imagen, la de realidad, las de objetividad y subjetividad, la de ficción y la de sentido. Pero no es éste el lugar adecuado para adentrarse en ellas, sino para subrayar que sus aportaciones, basadas en un notable esfuerzo interdisciplinar (y sin precedentes, desde la Periodística), suponen un punto de inflexión en los estudios académicos sobre las relaciones entre el Periodismo y la Literatura: propuso una línea de investigación que denomina el comparativismo periodístico-literario, se empeñó en que también se le abriera hueco en los estudios literarios y ha sido decisivo para que las nuevas formas expresivas fueran acogidas entre los académicos del Periodismo.

El asentamiento de la disciplina, la influencia estadounidense y la incorporación de nuevos estudiosos han hecho que a inicios de esta década el periodismo literario empiece a valorarse en los departamentos de Periodismo. Ya no hay temor al contagio, no se le ve como un elemento contaminante, sino como una riqueza.

\section{LO LITERARIO EN EL ARTÍCULO PERIODÍSTICO ESPAÑOL}

Inicialmente, y dado el peso de lo narrativo, fruto de la presión anglosajona en España en los años de la Transición, la academia prestó atención sobre todo a la naturaleza literaria del Periodismo narrativo. Cuando Lázaro Carreter (1979) y, posteriormente, Coseriu (1989) plantearon que no cabía un periodismo que fuera literatura estaban pensando en el periodismo como discurso narrativo y referencial (cfr. López Pan, 2005)7. También Chillón (1999: 195), presta una especial atención a la narratividad. De hecho, subraya que el periodismo ha sido desde el origen "en buena medida una cultura esencialmente narrativa", y sitúa el Periodismo literario como una variedad de la postficción característica de la escritura contemporánea.

De todos modos, no hay duda que el género español que más ha transitado la frontera entre el periodismo y la literatura es el artículo, como respalda el hecho

\footnotetext{
${ }^{7}$ Gutiérrez Carbajo y Martín Nogales, en el estudio introductorio de su antología de artículos literarios en prensa publicado en 2007, dedican la mitad del epígrafe titulado Literatura y Periodismo al debate iniciado por el Nuevo Periodismo, y aluden en él a las relaciones entre "documentación y ficción" $(2007,42)$.
} 
de que la polémica acerca de las relaciones entre Periodismo y Literatura ${ }^{8}$ surgiera en nuestro país en torno al artículo-ensayo y el artículo-narración (Palomo, 2007: 21). Pero, a pesar de su continua y prolongada presencia desde los tiempos de Larra, el género había quedado parcialmente orillado por la academia, tanto periodística como literaria. Afortunadamente, desde finales de los años 90, transmutado el género en columna, han aparecido diversos trabajos que lo abordan desde una perspectiva histórica, periodística y literaria.

Desde la perspectiva literaria, destacan los dos trabajos coordinados por Grohmann (2005 y 2006) y el que publican Gutiérrez Carbajo y Martín Nogales (2007). En el marco de la Periodística, sin ánimo de ser exhaustivos ${ }^{9}$, se pueden mencionar los de Santamaría (1989), León Gross (1996, 2005), López Hidalgo (1996 y 2005), López Pan (1996 y 2005), Santamaría y Casals (2000), Casals (2003), De Miguel (2005), Perlado (2007), Gutiérrez Palacio (2009), León Gross y Gómez Calderón (2008 y 2010). Varios de esos autores, bien es cierto que en algunos casos de modo tangencial, abordan la naturaleza periodística o literaria del artículo. Aquí traeremos algunas aportaciones en las que se advierten ciertas diferencias de matiz, pero un acuerdo casi generalizado.

Grohman (2006: 39) considera la columna como un género periodístico, pero afirma que la de escritores -la que estudia- es un género literario porque "una lograda columna de escritor es prueba de su esfuerzo, generalizado a todos los géneros literarios que cultiva, por dar a lo que comunica un valor permanente que mantenga el interés del lector una vez que lo que se comunica haya perdido actualidad". Muchas de esas columna expresan "las ideas, opiniones, obsesiones, sensaciones y sentimientos del autor" (Steenmeijer, 2006: 87), presentan un escaso componente informativo y documental -en los que la conexión con la actualidad puede darse o ser muy endeble- y destacan por la voluntad de estilo y la excelencia expresiva.

Martín Nogales, en la introducción a uno de los libros recopilatorios de las columnas publicadas por Pérez-Reverte ${ }^{10}$ en El Semanal, defiende la naturaleza

\footnotetext{
${ }^{8}$ Como bien señala Palomo, la publicación de poemas, novelas y cuentos en los periódicos no planteó ningún debate. Obviamente, el contexto obliga a ciertas adaptaciones; por ejemplo, en el caso del cuento, se reduce la extensión, se incluyen en algunos casos entradillas, se acompañan de imágenes, etc. Pero el soporte periodístico que "puede condicionar el texto" no lo "cuestiona genéricamente" (Palomo, 2007: 20).

${ }^{9} \mathrm{Hay}$ estudios sobre el trabajo de columnistas en concreto; sirvan de muestra: Martín García, M. (2004), Gómez Calderón, B. (2004 y 2008), García Álvarez, M. F. (2006), Herzberger, D. K. (2006), Sánchez Gómez, F. y Armañanzas, E. (2009). Y también se han publicado libros sobre la obra periodística de literatos: a modo de ejemplo, Aguirre Bellver, J. (1998), Echeverría, R. M. (1985), Revilla Guijarro, A. (2002), Ruiz-Ocaña, E. (2004): Vázquez Medel, M. A. (1999).

${ }^{10}$ Pérez-Reverte afirmaba en una entrevista que "periodismo es lo que hace Raúl del Pozo, un columnista que habla de la realidad. Lo mío es una mirada sobre el mundo, a veces un pensamiento, otras un cabreo. Es un ajuste de cuentas semanal. Un ajuste de cuentas muy subjetivo: no pretendo para nada informar, ni educar, ni transmitir, sólo expresar según esté feliz, simpático o de mala leche. Por eso digo que no es periodismo. La columna es un ejercicio de literatura que utiliza el periódico como medio. El periodismo es una cosa tan seria, tan cabal, tan concreta, tan nobilísimamente objetiva que no tiene ninguna vinculación con lo que hago" Entrevista de Tulio de Micheli en $A B C, 20$ de noviembre de 2005. Cita tomada de Peñalva (2008: 37).
} 
literaria del articulismo y se queja de que la teoría y la historia de la literatura, cuando no lo han ignorado, lo hayan considerado un género menor; un género que reivindica por su importancia cuantitativa, por su calidad y por su variedad $(20)^{11}$. Ahora bien, Martín Nogales también parece tener en mente el artículo /columna de escritores ya que la antología que publican años después Gutiérrez Carbajo y el propio Martín Nogales (2007) se centra en literatos que escriben de modo regular en prensa. $\mathrm{Y}$ al abordar las relaciones entre periodismo y literatura, hablan de escritores que han actuado como directores, impulsores y creadores de publicaciones periódicas, y que han escrito en la prensa tanto ensayos como piezas de ficción (entre otros, se alude a Baroja o a Valle-Inclán, varias de cuyas obras aparecieron publicadas en la prensa). De hecho, mencionan que esas columnas acentúan la dimensión pública de los escritores y "constituyen una especie de hermenéutica de las creaciones ajenas y de las suyas propias" (2007: 74). Aceptan la naturaleza bifronte del género, pero no la abordan de modo sustancial. Incluso da la impresión de que el mestizaje se ciñera exclusivamente al aspecto mencionado: escritores que escriben columnas y artículos en prensa.

También Perlado (2007: 35-40) se pregunta si en el artículo hay sólo periodismo o también literatura. A tenor del título de su libro,El artículo periodístico y literario, parece apostar por un género que comparta ambas naturalezas. $Y$, de hecho, habla de la relevancia de la palabra, y afirma que "es el cuidado exquisito por esa palabra -por su profundidad y por su orfebrería- la que hace y seguirá haciendo cada día el milagro de la literatura o del periodismo" (2007: 40). De todos modos, al igual que en los casos anteriores, sólo se menciona a escritores bien conocidos.

Para Pedro de Miguel (2005: 17), no hay duda de que el artículo es periodístico -así lo llama- y es literatura. A su juicio, "el problema (a la hora de clasificar la columna/artículo) estriba en defender una estricta clasificación de géneros u optar por la flexibilidad", de la que es partidario. Y en su antología sí aparecen articulistas que son periodistas: Emilio Romero, Eduardo Haro Tecglen, Pedro Rodríguez, Pilar Urbano o Arcadi Espada. Rebollo (2008: 75) afirma que la columna de algunos autores -menciona a Ruano, Alcántara y Umbral- "es literatura, es género literario", el último género literario; pero no deja de ser periodismo: es la "consagración del periodismo literario" (73). Por su parte, Gutiérrez Palacio (2009: 38), en la introducción a otra antología afirma con rotundidad la doble naturaleza del artículo, al que considera género estrella del periodismo literario en España.

Aunque cronológicamente precede a los anteriores, hemos reservado para el final la aportación de León Gross, quien, a nuestro juicio, ofrece algunas claves teóricas muy sugerentes. Al inicio de su artículo, recuerda cuestiones sabidas: que se trata de un género impreciso, periodísticamente incómodo, ubicado en

\footnotetext{
${ }^{11}$ También Valls afirma que es "un género tan importante como olvidado por los historiadores de nuestra literatura". Cita tomada de De Miguel (2005. 18).
} 
una zona de confusión, intermedia entre periodismo y literatura; que históricamente "proviene y se desarrolla de la tradición literaria de la que se extrapola estereotipadamente"; pero que "forma parte del sistema y de la estructura de modalidades textuales característicamente periodísticas" (2005: 6), por eso la Periodística lo acepta, pero argumentando que "que parcialmente el columnismo es una actividad extraperiodística pero in dejar de sostener que parcialmente es inequívocamente periodística" (7). Y esa división se refleja en las dos grandes tipologías: analíticas y literarias.

Frente a ese sí pero no todo de la Periodística, subraya que los dos grandes tipos de columnas tienen idéntica finalidad: influir en el lector, bien aportando argumentos o gracias al ingenio literario. $\mathrm{Y}$ concluye:

La columna es, así pues, un género, con variante pero sólo un género, y desde luego periodístico. A menudo éste sirve como soporte de expresión literaria, pero lo esencial es su función en el comentario de actualidad desde la 'propia voz'. Eso no excluye, en ningún caso que este género sea considerado como género literario con el valor perdurable que le es propio, pero, eso sí, sólo ocasionalmente funciona como género literario y siempre se trata de un género periodístico (León Gross, 2005: 8).

Más adelante, en el marco de nuestra propuesta, recuperaremos esta explicación; pero ahora corresponde preguntarse si el articulismo del que se viene hablando y las formas narrativas que utilizan recursos tradicionalmente patrimonio de la ficción son periodismo y literatura al mismo tiempo, o sea Periodismo literario. $Y$ eso pasa por definir qué entra en la esfera de lo literario.

\section{LITERATURA CONSTITUTIVA Y LITERATURA CONDICIONAL}

A lo largo de la historia, se han multiplicado los intentos de definir la literatura y distinguirla de otras realidades culturales: los formalistas rusos -que enfrentaban lenguaje poético a lenguaje práctico-; los estructuralistas del círculo de Praga -que formulan el concepto de desviación de la lengua literaria frente a la lengua estándar-; los formalistas, capitaneados por Jakobson -que hablan de función práctica y función estética-; quienes distinguen ambas actividades atribuyendo la denotación al lenguaje estándar y la connotación al literario. Pues bien, coincidimos con Chillón cuando, de la mano de De Girolamo, concluye que la Literatura es

un discurso construido socialmente; compuesto por una parte, por la intención literaria de quienes lo producen y por otra, sobre todo, por el reconocimiento y el sentido que le otorgan aquellos que son consumidores y consumadores: el acto literario se inicia en las manos del autor, cierto, pero solo se consuma en la lectura (1999: 33).

Más aún, a su juicio la literariedad de una obra no depende ni de los rasgos expresivos ni de la intención del autor: un texto cualquiera es literario "cuando es usado como tal por la comunidad de lectores", con independencia de la intención del autor y de sus características intrínsecas: sólo dependerá "de la manera como es evaluada e interpretada por el público" (1999: 19). Por lo tanto, afirma, 
lo literario no se reduce a las obras escritas que merecen entrar en un canon -según unos criterios que juzga discutibles e históricos- ni a las obras de ficción o imaginación; también debe acoger, junto a los géneros del periodismo literario mencionados, algunas modalidades de escritura documental, determinadas historias de vida y algunas narraciones sociológicas y antropológicas.

Ese carácter histórico y cambiante de la noción de Literatura es compartido por la comunidad académica. Una buena explicación la facilita Molino (1993: 3-28). El teórico francés sitúa la Literatura en dos ejes de variación. Uno, histórico, en el interior de cada tradición cultural (no se entiende lo mismo por la literatura, en Europa, en la Edad Media, en el Renacimiento...); y otro, geográfico según la diversidad de culturas. Precisamente, ante ese eje de coordenadas de variación, Molino sólo ve posible construir un inventario de lo que es literatura en cada momento sabiendo que tal inventario nunca llevará a la esencia de la literatura, "sino a un esclarecimiento de la noción en el que aparecerán dimensiones múltiples, correspondencias y evoluciones". Y concluye: "Desde el punto de vista metodológico, la literatura es un género similar a los otros" (27), y un género "no está fijo, se construye poco a poco, por un juego de respuestas, variaciones, innovaciones, discusiones sobre el corpus existente en cada instante, hasta que las publicaciones se ralentizan y el género continúa viviendo de una manera más discreta o incluso desaparece" (12 y 13). Y la modernidad, nuestro régimen, se caracteriza por

la mezcla, la rapidez de los ciclos y la coexistencia de géneros que revelan ritmos diferentes: es el caso, por ejemplo, de géneros de gran difusión, con constricciones genéricas fuertes y codificados con precisión -novela policíaca, de espionaje, de amor y de gran consumo-, que se oponen al ritmo precipitado de los modos de vanguardia (24).

Aunque parece indiscutible la naturaleza histórica y cambiante de lo literario y que un texto necesite ese reconocimiento social -que circule como literario- para que sea literatura ${ }^{12}$, entendemos que esa literariedad admitida no es fruto del capricho, sino resultado de la propia vida cultural, de la labor de los teóricos, de los críticos y los propios escritores que difunden y educan en el valor de lo literario. Por lo tanto, cabe preguntarse en qué coinciden los textos que de hecho se consideran literarios o qué caracteriza a lo que circula como literario en los distintos momentos. Respuestas -ya se ha visto- hay muchas; pero, a nuestro juicio, la más convincente es la explicación de Gerard Genette en su texto "Ficción y dicción", publicado en 1991, y matizado en 2003. El soporte teórico de Genette y las ideas desarrolladas más arriba desde la perspectiva de la Periodística nos servirán para formular la propuesta acerca del Periodismo literario con la que terminaremos este artículo. Antes, en lo que sigue, explicaremos con cierto detenimiento a Genette.

\footnotetext{
${ }^{12}$ Por cierto que este carácter cambiante de la Literatura es propio del Periodismo, en permanente evolución desde su nacimiento. También el periodismo es poliédrico, y se va enriqueciendo por adición de nuevas formas, renovación y adaptación de las tradicionales
} 
El autor francés empieza subrayando algo que considera indiscutible: la literatura es el uso artístico de la palabra. Y entonces, se pregunta: ¿qué hace de un texto una obra literaria o estética? Una de las respuestas -prosigue-, la más antigua, ha vinculado lo literario a la presencia de determinados temas o contenidos. Muchos han seguido los pasos de Aristóteles, para quien el lenguaje es creativo en la medida en la que se pone al servicio de la representación de acciones y acontecimientos inventados o imaginarios, o sea, al servicio de la ficción: para Aristóteles, el literato es literato por lo que cuenta, no por el modo de contar; es decir, lo es por la ficción no por la dicción. La ficcionalidad, concluye, es condición suficiente de lo literario ${ }^{13}$, pero -se pregunta- ¿es condición necesaria? A su juicio, no, porque ese criterio dejaría fuera a otros muchos textos de los que nadie ha puesto en entredicho su condición literaria, singularmente los líricos. Que la ficcionalidad no abriera la puerta a la lírica -explica Genette- llevó a los teóricos a buscar otro criterio también constitutivo de lo literario, es decir, suficiente. $Y$ se propuso el criterio formal, que acabó cuajando en la conocida función poética del lenguaje. Hay

un lenguaje poético -escribe- distinto del lenguaje prosaico u ordinario por características formales vinculadas superficialmente al empleo del verbo, pero más fundamentalmente a un cambio en el uso de la lengua, ya no tratada como un medio de comunicación transparente, sino como un material sensible, autónomo y no intercambiable (1991: 7).

Al universo de lo literario, se entraría pues, por dos puertas. Y ambas estarían cerradas a cal y canto para los textos periodísticos: la ficcionalidad impediría la entrada a los textos periodísticos narrativos ${ }^{14}$, y la lírica -lo poético en sentido fuerte-, a cualesquiera otros.

Pero Genette es consciente de que existen textos que son percibidos, sentidos e identificados como literatura -es decir, textos que circulan como literatura en la comunidad de lectores-, aunque no se ajusten a los criterios mencionados. Acepta que las esferas literarias de la ficción y de lo poético en sentido fuerte no abarcan, de hecho, todo el campo de lo literario: hay también -afirma- una "literatura no ficcional en prosa: historia, elocuencia, ensayo, autobiografía, por ejemplo" (1991: 9). Para esos casos $^{15}$ plantea el criterio de literariedad condicionalista, es decir, en ciertas circunstancias y bajo ciertas condiciones se convierte

\footnotetext{
${ }^{13}$ Según este criterio, al que me adhiero, determinados textos publicados en las columnas de periódicos serían simple literatura en periódicos. Es lo que sucede con los microrrelatos de Vicent o los articuentos de Millás.

${ }^{14} \mathrm{No}$ entraré en este artículo en la cuestión de si la ficcionalidad es una característica de toda narración, y por tanto inservible para trazar fronteras.

${ }^{15}$ Garrido Gallardo (2000) menciona la biografía, que se aleja del género histórico no sólo cuando hay presencia de fabulación, sino también cuando "el autor aprovecha para recrear una personalidad o para expresar sus emociones" (312), el ensayo, cuya "mayor o menor calidad con que se emplea la lengua establece la frontera entre el ensayo literario y el no literario" (313); la oratoria, con los "discursos que por la dignidad en la forma o la riqueza del fondo permanecen destinados a la fruición y personal enriquecimiento más allá de su uso originario" (314); y la crónica literaria: Campmany y Umbral (antes Azorín, Ruano, Pemán).
} 
en literario un texto que inicialmente cumple otras funciones -históricas, pedagógicas, etc.. Son condiciones de tipo subjetivo, pues la transformación tiene lugar cuando alguien "se interesa más por su forma que por su contenido [...], aprecia su redacción y al tiempo rechaza o pasa por alto su significación" (10). Cuando esto sucede, opera lo que llama la recuperación estética, que allega al arte lo que el "tiempo sustrae a la (esfera) de la verdad o la utilidad" (11). Esa es, por tanto, la puerta de entrada para textos pragmáticos, construidos con finalidades jurídicas, pedagógicas, filosóficas, etc., que, sin ajustarse a ninguno de los criterios constitutivos, podrían "entrar y salir de la esfera literaria al albur de las circunstancias y según ciertas condiciones" (9).

En conclusión, Genette plantea la existencia de una literatura de ficción, definida por unos contenidos fabulados, y una literatura de dicción -basada en el modo de decir-, que a su vez ampara la poesía, constitutivamente literaria, y la prosa no ficticia, que lo será de modo condicional. Así lo sintetiza en este cuadro:

Cuadro 1. Modos de literariedad posible según Genette.

\begin{tabular}{|l|c|c|}
\hline Régimen/ & Constitutivo & Condicional \\
\hline Criterio & FICCIÓN \\
\hline Temático & POESÍA DICCIÓN (2) \\
\hline Remático (1) PROSA \\
\hline
\end{tabular}

Fuente. Elaboración propia según indicaciones de Genette.

Usa "remático" como opuesto a temático y para referirse al ser del texto con el ser del texto: como "la «forma» (que una vocal sea abierta o cerrada, que una frase sea breve o larga, que un poema esté en octosílabos o en alejandrinos) no es sino un aspecto del ser de un texto o de uno de sus elementos" (13), prefiere un término que permita una mayor holgura. En segundo lugar, no separa los dos regímenes de la literaridad por dicción porque

la distinción entre prosa y poesía puede descansar en otros criterios, menos categóricos, que el de la versificación y que dichos criterios, por lo demás heterogéneos y más o menos acumulativos (por ejemplo: temas preferentes, densidad de «imágenes», disposición gráfica) dan paso, con el nombre de "poema en prosa», "prosa poética» o cualquier otro, a estados intermedios que confieren a esa oposición un carácter no rotundo, sino gradual y polar (13).

De sus matizaciones del 2003, aparte de afirmar la complementariedad de ambos regímenes -es decir, una obra puede ser reconocida como constitutivamente literaria y simultáneamente apreciada como obra de dicción-, lo más relevante a nuestros efectos es que pasa del plano general al caso particular de la crítica 
literaria, que considera literaria condicionalmente. $Y$ añade que en el caso de la literatura condicional que una obra sea literaria o no, se debe "simplemente a la inscripción, voluntaria o involuntaria, en un modo, constitutivo o condicional, de literariedad" (2003: 136). Por tanto, el talento es experimentado -y conferido- por la instancia pública, individual o colectiva que tiene la legitimidad para hacerlo. Dicho de otro modo, "la literariedad de un texto no ficcional o no poético [...] no depende esencialmente de la intención de su autor, sino de la atención de su lector", que lo hará sin consultarle y, con frecuencia, sin su conocimiento (2003: 138).

Este entramado teórico le sirve a Coquio -y Genette y Coquio nos servirán para las conclusiones del apartado final- cuando se plantea si el relato del sobreviviente (le récit du rescapé), el testimonio, es un género literario. Dice la citada autora que aceptar que es un género literario sería incorporarle al sistema literario como institución e historia, "lo que no es a priori, aunque tienda a llegar a serlo por la evolución de su recepción crítica" (2008: 109). Es decir, "el testimonio no nace texto literario, lo llega a ser o no" (121). Por tanto, no entra en lo literario de suyo, y en muchos casos esa entrada nunca tiene lugar. $Y$ añade: "La pertenencia de un testimonio a la literatura se mide y analiza texto a texto, por el estudio de sus formas y sus modos de enunciación" (124). Esta idea del reconocimiento selectivo de los textos tendrá especial relevancia en la propuesta que sigue.

\section{CONCLUSIONES}

Aunque es el punto en el que menos se ha insistido, entendemos que todos los géneros del llamado Periodismo literario son constitutivamente periodismo. Lo son los narrativos: buena parte de la academia periodística, aunque no sólo, les ha dado carta de naturaleza a esas fórmulas expresivas. Respecto al artículo, coincidimos con León Gross cuando afirma que es un género, aunque en alguna ocasión es también literatura: "Sencillamente se puede hacer literatura también en el periodismo, y no por eso se está dejando de hacer periodismo" (2005: 8). Sobre esto, volveremos más adelante.

Obviamente, son periodismo siempre que el periodismo desborde las definiciones más tradicionales, y se entienda en los términos de Chillón: como una profesión intelectual, ejercida por auténticos escritores que no han de quedar constreñidos en sus posibilidades expresivas por las limitaciones impuestas por una falsa e imposible objetividad ${ }^{16}$. En ese sentido -y en buena medida nos sumamos a su explicación-, el periodismo no es un simple oficio práctico, sometido a una serie de convenciones estilísticas: a su juicio, no existe un estilo o un

\footnotetext{
${ }^{16}$ Porque, como ha señalado al hablar del giro lingüístico, el lenguaje es inevitablemente retórico y simbólico, y no actúa como una simple copia de un pensamiento que ha captado una realidad externa. Esto le lleva a subrayar el carácter ficticio de todo discurso, por tanto, también el Periodístico, aunque en éste esa ficcionalidad sea implícita y no intencional.
} 
lenguaje periodístico uniforme; al menos, si este se entiende de modo reductivo como considera que se ha hecho en el ámbito de la Redacción Periodística.

El llamado Periodismo literario ampara "escritos que son Periodismo porque en ellos manda la actualidad, el interés y la comunicabilidad, y porque están escritos con el triple propósito de informar, orientar o distraer" (Yanes Mesa, 2004: 293). Y no hay que confundirlos con la literatura que se publica en la prensa o literatura periodística: "Escritos netamente literarios, no sólo por su lenguaje, creativo y sin límites de expresión, sino también por sus contenidos, aunque están publicados en las páginas de un diario" (2004: 296).

Los textos del Periodismo literario son constitutivamente periodismo y condicionalmente literatura. En buena medida esta opción se acomoda bien a la que planteaba León Gross para el artículo cuando afirmaba que es siempre periodismo y a veces literatura. Ahora bien, en los términos de Genette y Coquio, pensamos que no es el género el que entra en la esfera de lo literario, sino cada texto individualmente. Es decir, el artículo -también la crónica, la entrevista, el reportaje o el perfil- es un género periodístico, algunos de cuyos textos devienen literarios y se incorporan a esa categoría de Periodismo literario. En el fondo, esa es la idea que late en el párrafo con el que cierra León Gross (2009: 31) la antología de diez articulistas para la historia de la literatura:

La historia del articulismo es un puzzle interminable de nombres propios. El género está destinado a consumirse en el día a día, y pocas firmas sobreviven a este carrusel que se acaba devorando a sí mismo. Esos nombres, sin embargo, han contribuido a que resulte imprescindible un espacio para el artículo en la Historia de la Literatura.

Aunque, como se ha visto más arriba de la mano de Chillón, lo literario no depende exclusivamente de los rasgos lingüísticos, no hay más remedio que admitir que

habitualmente una especial elaboración del lenguaje es síntoma de que nos encontramos ante un fenómeno literario. Dicha elaboración puede estar puesta por el autor conscientemente al servicio de una intención originariamente literaria a tenor de las reglas de un género determinado o puede haber surgido de modo espontáneo como calidad de escritura no prevista ${ }^{17}$.

Si en la esfera literaria de lo condicional se entra por la calidad y se exige el talento, es lógico que los artículos con la firma de escritores -que trasladan a sus textos las cualidades que les hacen destacar como escritores, con su peculiar mirada a la realidad y la manera de expresar sus ideas- sean candidatos firmes a la literatura condicional. Además, en tanto que profesionales de la literatura sus

\footnotetext{
${ }^{17}$ Lo normal será que en el primer caso los recursos sean más frecuentes y sistemáticos que en el segundo, pero eso sólo no es garantía de mayor calidad: un poema demasiado elaborado puede resultar de una pesadez insoportable (Garrido Gallardo, 2000: 26).
} 
artículos son más fácilmente aceptados en el ámbito de lo literario. Por estas razones, no es extraño que en las antologías referenciadas a lo largo de este trabajo aparezcan casi exclusivamente literatos.

\section{REFERENCIAS BIBLIOGRÁFICAS}

ACOSTA MONTORO, J. (1973): Periodismo y literatura I y II. Madrid: Guadarrama.

AGUILERA PERELLÓ, O. (1992): La literatura en el periodismo: $y$ otros estudios en torno a la libertad y el mensaje informativo. Madrid: Paraninfo.

AGUIRRE BELLVER, J. (1998): Azorín, cronista de Cortes. Alicante: Instituto de Cultura "Juan Gil Albert".

AUCOIN, JAMES L.: "Epistemic responsibility and narrative theory. The literary Journalism of Ryszard Kapuscinski". Journalism, vol. 2, no 12 (2001), pp. 5-21.

BERNAL, S. y CHILLÓN, A. (1985): Periodismo informativo de creación. Barcelona: Mitre.

CANTAVELLA, J. (2002): La novela sin ficción: cuando el periodismo y la narrativa se dan la mano. Oviedo: Septem.

CASALS, M. J.: "Juan José Millás. La realidad como ficción, la ficción como realidad o cómo rebelarse contra los amos de lo real y del lenguaje. Análisis de Juan José Millás, columnista de El País", Estudios sobre el mensaje periodístico, nº 9 (2003), pp. 63-124.

CHILLÓN, LL. A. (1999): Literatura y Periodismo: una tradición de relaciones promiscuas. Bellaterra: Universidad Autónoma de Barcelona.

- "Las escrituras facticias y su influjo en el periodismo moderno", Trípodos, $n^{\circ} 19$ (2006), pp. 9-23.

COQUIO, C.: "Le réciti du rescapé est un genre littéraire" ou le tegmoignage comme "genre de travers'. En MONCOND'HUY, D. y SECPI, H. (ed.) (2008): Les génres de travers. Litterature et trnasgénéricité. Rennes: La Licoren, Press Universitaries de Rennes, pp. 103-131.

COSERIU, E.: "Información y literatura", Comunicación y Sociedad, vol. 3, no 1 y 2 (1990), pp. $185-200$.

CHALABY, J. K. (1998): The invention of journalism. Houndmills, Basingstoke, Hampshire: Macmillan Press; New York: St. Martin's Press.

DE MIGUEL, P. (2005): Articulismo español contemporáneo. Una antología. Madrid: Marenostrum.

ECHEVERRÍA, R. M. (1985): Wenceslao Fernández Flórez: su vida y su obra (creación, humor y comunicación). La Coruña: Diputación Provincial de La Coruña.

FERNÁNDEZ PARRATT, S. (2003): Introducción al reportaje: antecedentes, actualidad y perspectivas. Santiago de Compostela: Universidad de Santiago de Compostela.

GARCÍA ÁlVAREZ, M. F.: El lector intratextual en las columnas de Rosa Montero. En GROHMANN, A.; y STEENMEIJER, M. (ed.) (2006). El columnismo de escritores españoles (1975-2005). Madrid: Verbum, pp. 175-197. 
- "Las columnas de autor: Retórica y... ¿Diálogo? Caso práctico: la presencia del 'otro' en el columnismo de Rosa Montero", Estudios sobre el mensaje periodístico, n 13 (2007), pp. 399-417.

GARRIDO GALLARDO, M. A. (2000): Nueva introducción a la Teoría de la Literatura. Madrid: Síntesis.

GENETTE, G. (1991): Ficción y Dicción. Barcelona: Lumen.

- "Fiction ou diction", Poétique, no 134 (2003), pp. 131-139.

GÓMEZ CALDERÓN, B.: La columna diaria de Manuel Alcántara. Apuntes para una retórica. En LEÓN GROSS, T. (dir.); y GÓMEZ CALDERÓN, B. (ed.) (2008): El artículo literario: Manuel Alcántara. Málaga: Servicio de Publicaciones de la Universidad de Málaga, pp. 85-98.

- (2004): Ladrón de fuego: la obra en prensa de Francisco Umbral. Madrid: I+D Com.

GONZÁLEZ RUIZ, N. (ed.) (1953): El Periodismo. Teoría y práctica. Barcelona: Noguer.

GROHMANN, A.: "La escritura impertinente", Ínsula: Revista de Letras y Ciencias Humanas, $\mathrm{n}^{\circ}$ 703-704 (2005), pp. 2-5.

GROHMANN, A.; y STEENMEIJER, M. (eds.) (2006): El columnismo de escritores españoles (1975-2005). Madrid: Verbum.

GUTIÉRREZ CARBAJO, F.; y MARTÍN NOGALES, J. L. (eds.) (2007): Artículos literarios en la Prensa (1975-2005). Madrid: Cátedra.

GUTIÉRREZ PALACIO, J. (coord.): (2009): De Azorín a Umbral. Un siglo de periodismo literario español. La Coruña: Netbiblo.

HALLIN, D. C.; y MANCINI, P. (2004): Comparing media systems: three models of media and politics. Cambridge; New York: Cambridge University Press.

HARTSOCK, J. C.: "Note from the editor...", Literary Journalism Studies, vol. $1, \mathrm{n}^{\circ} 1$ (2009), p. 5.

- 'Literary Journalism' as an Epistemological Moving Object within a Larger 'Quantum' Narrative", Journal of Communication Inquiry, vol. 23, $\mathrm{n}^{\circ} 4$ (1999), pp. 432-447.

- "The critical Marginalization of America Literary Journalism", Critical Studies in Mass Communication, vol. 15 (1998), pp. 61-84.

HERZBERGER, D. K.: La disciplina de escribir: el columnismo literario de Antonio Muñoz Molina. En GROHMANN, A.; y STEENMEIJER, M. (eds.) (2006): El columnismo de escritores españoles (1975-2005). Madrid: Verbum, pp. 45-58.

KRAMER, M.: Breakable Rules. En SIMS, N.; y KRAMER, M. (eds.) (1995): Literary journalism: A New Collection of the Best American Nonfiction, New York: Ballantine Books, pp. 21-34.

LEÓN GROSS, T. (1996): El artículo de opinión: introducción a la historia y la teoría del articulismo español. Barcelona: Ariel.

- "La columna y lo literario como valor periodístico", Ínsula. Revista de Letras y Ciencias Humanas, 703-704 (2005), p. 5-8. 
LEÓN GROSS, T.; y GÓMEZ CALDERÓN, B. (dirs.) (2009): Diez articulistas para la historia de la literatura española. Madrid: Asociación de la Prensa de Madrid, Asociación de la Prensa de Cádiz, Fundación Manuel Alcántara y Fragua.

- (eds.) (2008): El artículo literario: Manuel Alcántara. Málaga: Servicio de Publicaciones de la Universidad de Málaga.

LÓPEZ HIDALGO, A. (1996): Las columnas del periódico. Madrid: Libertarias-Prodhufi.

- "Realidad y ficción en la columna periodística". Ínsula: Revista de Letras y Ciencias Humanas, n 703-704 (2005), pp. 18-20.

LÓPEZ PAN, F.: “¿Es posible el Periodismo literario? Una aproximación conceptual a partir de los estudios de Redacción Periodística en España en el período 1974-1990”, Doxa Comunicación, vol. 3 (2005), pp. 11-31.

- (2004): "Siete rasgos de la Periodística como disciplina universitaria". Ponencia presentada en el Foro Universitario de Investigación en Comunicación, dentro del VIII Ciclo de Otoño, 24 de noviembre [en prensa].

- "Breve historia de las relaciones entre la Lengua y la Redacción Periodística", Español actual, $\mathrm{n}^{\circ} 79$ (2003), pp. 99-108.

MARTíN GARCíA, M.: "La travesía de Antonio Muñoz Molina en El País. Análisis de Antonio Muñoz Molina en sus artículos de prensa". Estudios sobre el mensaje periodístico, no 10 (2004), pp. 279-296.

MARTín NOGALES, J. L.: Larra en los Balcanes. En PÉREZ-REVERTE, A. (1998): Patente de Corso. Madrid: Alfaguara, pp. 13-29.

MARTín NOGALES, J. L.: Testigo del siglo. En PÉREZ-REVERTE, A. (2001): Con ánimo de ofender. Madrid: Alfaguara, pp. 13-22.

MARTÍN VIVALDI, G. (1973): Géneros periodísticos: Reportaje, crónica, artículo (Análisis diferencial). Madrid: Paraninfo.

MARTÍNEZ ALBERTOS, J. L. (1992): Curso general de redacción periodística: lenguaje, estilos y géneros periodísticos en prensa, radio, televisión y cine. Madrid: Paraninfo. Edición revisada.

- (1978): La noticia y los comunicadores públicos. Madrid: Pirámide.

MOLINO, J.: "Les genres littéraires", Poétique, vol. 24, nº 93 (1993), pp.3-28.

MONCOND'HUY, D.; y SCEPI, H. (eds.) (2008): Les genres de travers. Litterature et trnasgénéricité. Rennes: La Licoren, Press Universitaries de Rennes.

-Avant-propos. En MONCOND'HUY, D.; y SCEPI, H. (eds.) (2008): Les genres de travers. Litterature et trnasgénéricité. Rennes: La Licoren, Press Universitaries de Rennes, pp. 7-11.

PALOMO VÁZQUEZ, M. P. (2007): Periodismo/Literatura (Notas de aproximación), Departamento de Filología Española III, Facultad de Ciencias de la Información, Universidad Complutense de Madrid.

PEÑALVA, J. L. (2008): El loco de la columna. Peñalva versus Andrews. Bilbao: Servicio Editorial de la Universidad del País Vasco. 
PÉREZ-REVERTE, A. (1998): Patente de corso (1993-1998). Madrid: Alfaguara.

PERLADO, J. J. (2007): El artículo literario y periodístico: paisajes y personajes. Madrid: Ediciones Internacionales Universitarias.

REBOLLO SÁNCHEZ, F.: "Lo literario en la columna periodística", Ínsula: Revista de Letras y Ciencias Humanas, $\mathrm{n}^{\circ}$ 703-704 (2005), pp. 23-25.

REVILLA GUIJARRO, A. (2002): Periodismo y literatura en la obra de Julio Camba. Pontevedra: Diputación Provincial de Pontevedra, Servicio de Publicaciones.

RODRÍGUEZ RODRÍGUEZ, J. M.: "Gómez Alfaro: pionero de los estudios interdisciplinariossobre las relaciones entre Periodismo y Literatura en España", Revista Latina de Comunicación Social, no 65 (2010), pp. 89-98. Disponible en http://www.revistalatinacs. org/10/art/885 USJ/07_Jorge Rodriguez.html [Consulta: 7 junio 2010].

RUIZ-OCAÑA, E. (2004): La obra periodística de Emilia Pardo Bazán en La llustración Artística de Barcelona (1896-1915). Madrid: Fundación Universitaria Española.

SÁNCHEZ GÓMEZ, F.; y ARMAÑANZAS, E.: "Carmen Rigalt, columnista de El mundo", Tonos Digital, no 17 (2009), pp. 1-57.

SANTAMARÍA, L. (1990): El comentario periodístico. Los géneros persuasivos. Madrid: Paraninfo.

SANTAMARÍA, L.; y CASALS, M. J. (2000): La opinión periodística. Argumentos y géneros para la persuasión. Madrid: Fragua.

SIMS, N. (ed.) (1984): The Literary Journalists. New York: Ballantine Books.

- (ed.) (1990): Literary Journalism in the Twentieth Century. New York: Oxford University Press.

- "The problem and the Promise of Literary Journalism Studies", Literary Journalism Studies, vol. 1, no 1 (2009), pp. 7-16.

STEENMEIJER, M.: Javier Marías, columnista: el otro, el mismo. En GROHMANN, A. y STEENMEIJER, M. (eds.) (2006): El columnismo de escritores españoles (1975-2005). Madrid: Verbum.

VÁZQUEZ MEDEL, M. A. (1999): La obra periodística y ensayística de Rafael Sánchez Ferlosio. Sevilla: Alfar.

VIDAL, D.: "La transformació de la teoria del periodisme: una crisi de paradigma?, Anàlisi, $\mathrm{n}^{\circ} 28$ (2002), pp. 21-54.

YANES MESA, R. (2004): Géneros periodísticos y géneros anexos: una propuesta metodológica para el estudio de los textos publicados en prensa. Madrid: Fragua.

\section{Breve semblanza biográfica del autor}

Fernando López Pan es Profesor de Periodismo en la Universidad de Navarra. Ha publicado varios estudios sobre la columna y el libro La columna periodística. Teoría y práctica. También es autor de una veintena de artículos especializados en escritura periodística, entre ellos, dos sobre Periodismo literario. Ha sido director del Departamento de Proyectos Periodísticos (1999-2005) y vicedecano de la Facultad de Comunicación (2005-2008). 
116 Periodismo literario: entre la literatura constitutiva y la condicional

También ha formado parte del Consejo de Dirección de la revista mensual de cuestiones de actualidad Nuestro Tiempo.

(Recibido el 27-08-2009, aceptado el 26-03-2010) 